\title{
Educational paths in Romania: choosing general or vocational education
}

\author{
Monica Mihaela MAER MATEI, \\ National Research Institute for Labour and Social Protection, Romania \\ matei.monicamihaela@gmail.com \\ Cristina MOCANU,
} National Research Institute for Labour and Social Protection, University of Bucharest, Romania mocanu@incsmps.ro Ana-Maria ZAMFIR, National Research Institute for Labour and Social Protection, Romania anazamfir@incsmps.ro

\begin{abstract}
Education is a key factor that can contribute to the economic growth, supporting the social mobility and the living standard improvement. Both from the scientific point of view, as well as from the policy making process point of view, it is essential to know how individuals choose their educational path, in order to understand what is and can be the role of different educational routes in ensuring social mobility and improving standard of living. In this article we explore the factors that explain attitudes and decisions of individuals for vocational vs. general education in Romania. Our analysis is based on data from a national survey among adult Romanian population. Attitudes regarding the choice of vocational vs. general education are analysed by employing decision trees method in order to assess the extent to which vocational education is considered a valuable education path or an educational alternative for those with lower socio-economic background.
\end{abstract}

Keywords: vocational education, general education, inequalities, stratification, decision trees JEL Classification: I24, I26

\section{Introduction}

Education is a key factor that can contribute to the economic growth, supporting the social mobility and the living standard improvement. The income of the individuals is influenced by their productivity, which depends on the 
acquired skills and education. Vocationally oriented education has been changing in the recent years in Europe as VET is currently expanding and diversifying. The changing content and role of vocational education requires to better understand how individuals are classified in their choices for different educational routes vocational vs. general - and which are the factors that influence this process of segmentation.

The financial and non-financial benefits expected by individuals when graduating a specific educational program motivate them to decide to postpone the consumption of present revenues in the favour of the potential ones. Both from the scientific point of view, as well as from the policy making process point of view, it is essential to know how individuals choose their educational path, in order to understand what is and can be the role of education in ensuring social mobility and improving standard of living. So, the goal of this article is to explore the factors that explain attitudes and decisions of individuals for vocational vs. general education in Romania. Our analysis is based on data from a national survey among adult Romanian population. Attitudes regarding the choice of vocational vs. general education are analysed by employing decision trees method in order to assess the extent to which vocational education is considered a valuable education path or an educational alternative for those with lower socio-economic background.

While analysing the educational decisions of individuals and anticipated returns from education in various national contexts, one must consider that in some countries, too rigid labour market regulations and institutions tend to compress the benefits associated to different educational programs (Education at a glance, OECD, 2012). In the Romanian context, the subject of this article is of high relevance, given that the reform of the educational system has been one of the priorities of the public agenda from many years. Moreover, the vocational component of the Romanian educational system was subject to successive reforms and changes, some of them quite contradictory.

\section{Literature review}

One of the most important results of a recent cross-country analysis on the changing nature and role of VET in Europe is that this route of education has become more individualised meaning that it is characterised by more individualised pathways and more heterogeneous groups of students (CEDEFOP, 2017). 
Nilsson (2010) has analysed empirical evidences supporting the two major reasons that have substantiate the revival of vocational education and training: promotion of economic growth and fostering social inclusion. His meta-analysis has showed that VET is beneficial for social inclusion and, possible, to economic development, especially in developing countries (Nilsson, 2010).

Other studies showed that vocational education has been associated $\mathrm{cu}$ increased level of wages (Mane, 1999; Bishop and Mane, 2004) and better education-job match in first jobs (Arum and Shavit, 1995; Heijke et al., 2003; Giret, 2011). Verhaest and Baert analysed the long-term effects of vocational education programs and found no evidence on a trade-off between higher employment rates and better match at the beginning of the career and higher risk of mismatch persistence for those entering in mismatched jobs (Verhaest and Baert, 2015).

In those countries with educational systems that include a strong vocational component, which is aiming to prepare individuals for the labour market, respectively in the countries with a stratified educational system (the pupils orientation towards the general or vocational education takes place at an early age) and where the social partners are involved in the educational process, obtaining a vocational qualification is attractive for the young people and it is associated with significant benefits on the labour market (Müller and Gangl, 2003). By contrast, in the countries where the educational systems are oriented, mainly, to provide to the graduates' general knowledge and competencies, the vocational component is developed as a residual alternative to the general educational path. In the absence of the active involvement of the social partners, the programmes of vocational education from these countries develop through the imitation of the functioning modality of the general programmes. In these countries, obtaining a vocational qualification represents in fact an indicator of a low level of general knowledge and competencies, instead of indicating a high level of specific competencies. As follows, it is expected that these qualifications generate lower benefits on the labour market, and the graduates of general education, especially tertiary, can enjoy higher revenues (Estevez-Abe, 2001).

The perceptions and importance attributed to general and vocational skills started recently to be questioned by European Commission $(2011,2014)$ and comparable findings are relevant for a better understanding of people expectations and the potential impact of different reform options.

Eurobarometer 417 "European area of skills and qualification" (European Commission, 2014) is one of few comparative data sources on how much people value different types of skills. As Table 1 evidences, basic skills (such as reading, 
writing, numeracy) are the most valued ones, and Romania scores pretty close to the EU average. Job-specific skills tend to be less valued, as against basic ones, but Romania, mainly due to the high percentage of people with vocational degrees, seems to put a higher premium on vocational-oriented education. What distinguishes Romania is the low premium attributed to transferable skills (such as problem solving, teamwork) as well as on skills for specific subjects (such as law, science and technology, etc.). The last two types of skills are valued mainly by persons with high level of education, while those with low level of education rather value basic skills, as these are the skills they possess (European Commission, 2014). So, Romania seems to be a country that values basic skills, in other words low levels of general education, and invest less in job-specific, transferable or specialized skills.

Table 1. Perceptions on the importance of skills provided by the educational system in Romania and EU (\% of those considering important the ...), Source: European Commission (2014)

\begin{tabular}{|l|c|c|c|c|c|}
\hline & $\begin{array}{c}\text { Basic } \\
\text { skills }\end{array}$ & $\begin{array}{c}\text { Job- } \\
\text { specific } \\
\text { skills }\end{array}$ & $\begin{array}{c}\text { Transferable } \\
\text { skills }\end{array}$ & $\begin{array}{c}\text { Specialised } \\
\text { skills in } \\
\text { subjects such } \\
\text { as science, } \\
\text { law, etc. }\end{array}$ & $\begin{array}{c}\text { Foreign } \\
\text { languages }\end{array}$ \\
\hline Romania & 61 & 38 & 15 & 19 & 21 \\
\hline EU average & 62 & 34 & 30 & 26 & 24 \\
\hline
\end{tabular}

The Special Eurobarometer 369 "Attitudes towards vocational education and training" (2011) points out to a mixed image of vocational education and training (VET) in Romania. Although the role of VET for the economy is positively assessed, the skills provided by VET education are considered matched only to a low extent to employers' needs, leading to employment in jobs that are low paid or with poor career prospects. (European Commission, 2011).

Table 2. Pupils enrolled in upper-secondary education by vocational oriented tracks (\%), Source: Eurostat, [educ_uoe_enrs05]

\begin{tabular}{|l|c|c|c|c|}
\hline & 2013 & 2014 & 2015 & 2016 \\
\hline Romania & 60.0 & 57.2 & 56.3 & 56.2 \\
\hline EU average & 48.9 & 48.0 & 47.3 & $\ldots$ \\
\hline
\end{tabular}


Data on the demand side of education - people perceptions have to be analysed as against the supply side of education - how the cohorts are tracked to general and vocational skills. When looking to the share of VET in the total number of pupils enrolled in upper-secondary (see Table 2), one can see that in Romania more than half of high-school age pupils are enrolled in vocational education, much more the EU average. Although the enrolment in VET is on a decreasing trend, it still remains at higher levels compared with other EU countries.

So, data indicate to a mismatch between people expectations and values, oriented to more general skills and the educational supply that is more oriented to vocational skills.

\section{Data and methods}

Data used for the present paper were collected through a national representative survey on 1010 persons, aged 18+ years old, the sampling error being up to $\pm 3.1 \%$ (commissioned by INCSMPS). Several items on populations' behaviour and intentions of participation to education and continuing vocational training were included in a monthly omnibus carried out by IMAS Marketing and Polls. Data were collected between 16th of May - 7th of June 2017 through a CATI (Computer Assisted Telephone Interviewing) approach. In order to design the random sample, 20588 telephone number were automatically generated by a computer, out of which 12409 were valid and constituted the research universe for the survey. The sample covered all regions and counties of Romania. The final sample was weighted in order to balance the sample structure on gender, age and ethnicity.

For the purpose of this paper, in order to have a higher consistency of the findings, 10 youth of 18 years old were excluded from the sample. So, the final data set used for analyses was up to 1000 persons aged 19+ years old.

The goal of this study is to identify which are the drivers of the propensity towards a specific educational route at secondary level. Therefore, we built a binary classifier aiming to predict the preferences for one of the two categories: General high school or Vocational high school. The classification is developed using CART (Classification and Regression Trees) methodology (Breiman et al., 1984). The arguments supporting the selection of this type of classifier are mainly based on the following properties: (i) interaction effects among different variables are tested without worrying about the curse of dimensionality, (ii) trees represent a natural way of partitioning the data and it is very easy to understand by nonstatistician decision makers. 
When using CART method, the classification is achieved by successive binary partitions based on different predictors. The partitioning procedure creates subsets that are called nodes. The terminal nodes are known as leaves and they are assigned the class most frequently found in that subset. In a very simplified formulation, we start with a root node comprising all our individual data and at each step the algorithm finds the optimal split based on the characteristics used to predict class membership. From all the combinations of splitting rules, the procedure selects the one implying the maximal decline in impurity or diversity. The impurity concept captures also the risk of incorrect classification and it is usually measured by the Information or Gini index (Atkinson, Therneau, 2000). This recursive partitioning stops when a certain criterion is met. In most cases, these are related to the minimum number of observations that must exist in a node in order to introduce a new split or with the classification improvement. The former criterion states that any split that does not improve the fit by a pre-defined value is not attempted (Atkinson, Therneau, 2000). In this paper, the tree was grown using the default value of 0.01 , implemented in rpart $\mathrm{R}$ routine (Therneau et al., 2018). The splitting index was the information impurity where the probabilities are computed using the observed data frequencies.

To sum up, we will grow a tree on the basis of four explanatory variables in order to predict the educational route individuals value the most. When building the decision tree, we used two categorical variables, namely "Gender" and "Educ" and two numerical variables denoted "Age" and "Income". Gender is a categorical variable with two levels, labelled $M$ (Male) and $F$ (Female) and Educ is a variable with four levels, showing the education level of the respondent, labelled as follows: "1" (Primary education /Gymnasium), "2" (Vocational high school or lower cycle of high school), "3" (Upper cycle of High School and/or post-secondary education) and " 4 " (higher education). The Income variable measures the total net income in the respondent's household.

The outcome is a binary variable built upon the answers to the question: "Which would be your advice for a 15-year-old person wishing to attend high school?". The respondent had two options: (1) I would advise him/her to choose a general high school or (2) I would advise him/her to choose a vocational route. In the investigated dataset, there is a slight prevalence of the second category with a relative frequency of $54.4 \%$.

The classification tree is represented in Figure 1 which also provides the classification rules. The graphical representation of the classifier includes the main elements discussed in the previous paragraphs: each branch is described by the splitting criteria and each terminal node is described by the label of the predicted 
class, the probability of the second class and the percentage of observations in the node (Milborrow, 2016).

Table 3. Variable importance

\begin{tabular}{|l|c|c|c|c|}
\hline Variable & Age & Income & Educ & Gender \\
\hline Importance & 41 & 39 & 16 & 5 \\
\hline
\end{tabular}

The main predictor variable is the Age due to the incidence to which it is selected as splitting criteria. Table 3 shows an overall measure of variable importance where the values are scaled to sum to 100 .

\section{Main findings}

As said before, the first factor identified as influencing the preference for vocational or general educational tracks is age. Those under 25 years old have a strong preference for general education, $72 \%$ of them declaring they would recommend a general track to youth aged 15 years old and having to make their educational choice.

The second factor influencing the educational preferences is the household income. As table 3 evidences, there is a small difference in between the importance of age and income as segmentation factors. Those with a household income under 2450 lei (aprox. 530 euros) prefer vocational training. So vocational path seems to respond better to the needs and resources of those coming from low-income households.

For those with age of $25+$ years old and belonging to households with incomes higher than $\mathbf{2 4 5 0}$ lei, the most important factor of influence is education. Persons with low level of education (level 1 - primary education or gymnasium) prefer vocational education. So, those with no qualification put a premium on pathways that provide a qualification and slightly better prospects on the labour market as compared with their current position and opportunities.

The forth factor is gender. For each gender, income and age are subsequent factors influencing the preference for different educational pathways. Women from households with incomes close to the lower bottom of the income distribution or with ages under 59 years old prefer general education, while older women, mainly educated under communist regime, prefer vocational education. On the other hand, male from households with very high incomes $(7750+$ lei) or with ages higher than 31 years old prefer vocational training, while younger man rather prefer general education. Thus, those guiding youth to vocational education 
are rather men that benefited of high education returns due to their voluntary or rather constrained choices carried out during communism. The women preference for general education could be explained by their career choices usually for public administration or support/logistic activities.

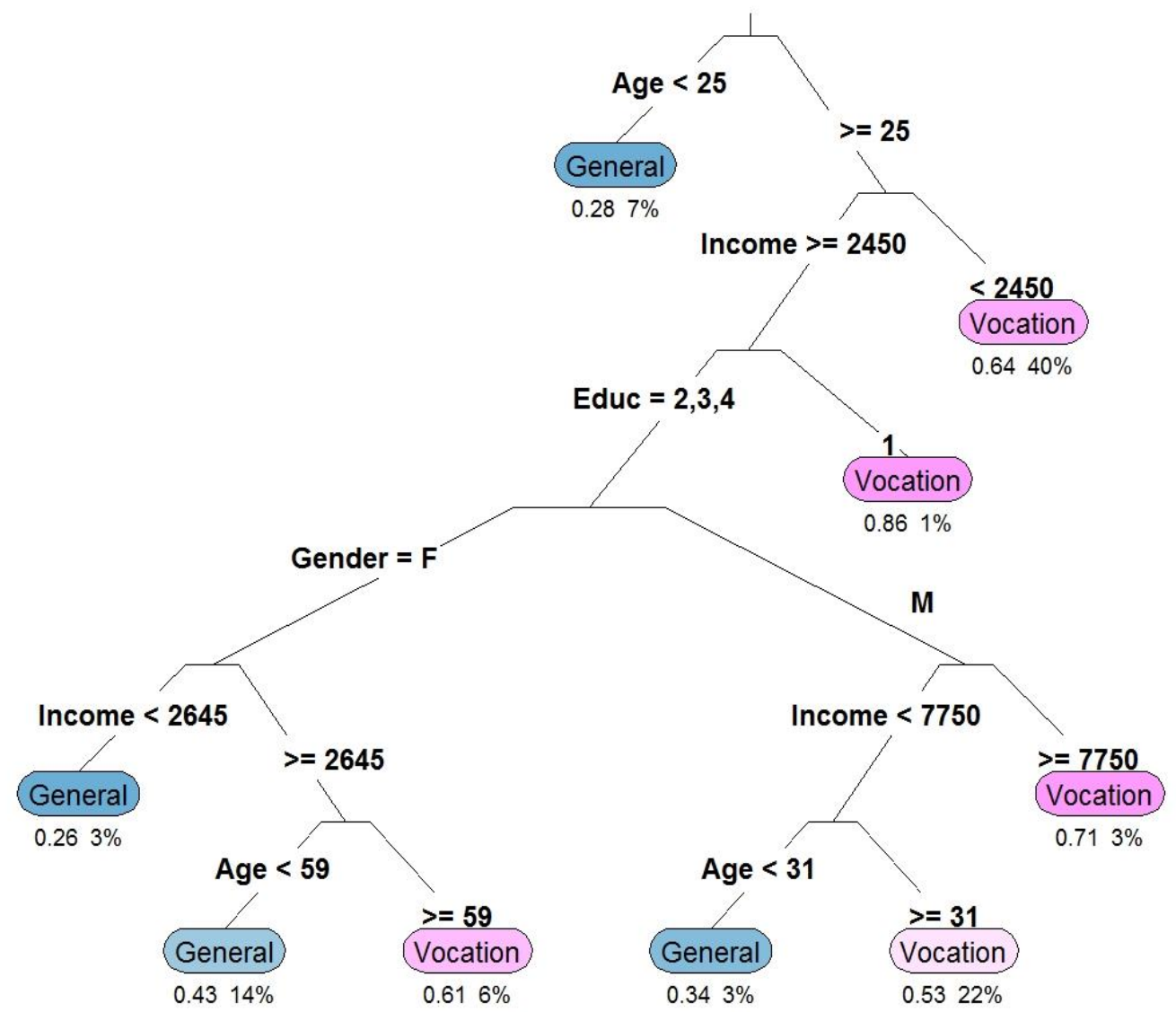

highschool Gen Voc

General $[.74 .26]$ when Age $>=$

General $\left[\begin{array}{ll}.72 & .28\end{array}\right]$ when Age $<25$

25 \& Income is 2450 to 2645 \& Educ is 2 or 3 or 4 \& Gender is $F$

cover

General [.66 .34] when Age is 25 to 31 \& Income is 2450 to 7750 \& Educ is 2 or 3 or 4 \& Gender is $M$

General [.57 .43] when Age is 25 to 59 \& Income $>=\quad 2645$ \& Educ is 2 or 3 or 4 \& Gender is $\mathrm{F} \quad 14 \%$

vocational $[.47 .53]$ when Age $>=$

Vocational $[.39$.61] when Age $>=$

31 \& Income is

Vocational $[.36 .64]$ when Age $>=$

$59 \&$ Income $>=$

$25 \&$ Income $<2450$

Vocational $[.29$.71] when Age $>=$

$25 \&$ Income $>=$

2645 \& Educ is 2 or 3 or 4 \& Gender is $F$

25 \& Income >=

7750 \& Educ is 2 or 3 or 4 \& Gender is $M$ 2450 \& Educ is

1

Figure 1 Classification tree, Source: authors' estimations 


\section{Conclusions}

To conclude, youth and women rather value general education, while those with higher ages, with low level of education or belonging to households with low income levels rather opt for vocational.

As Table 3 evidenced, age and income are the most important factors influencing the preferences for different educational pathways. The older ones, rather male, as well as those belonging to households with lower levels of income prefer vocational education. The older ones are most of them educated under the communist regime, being characterized by higher valorisation of vocational qualification for industry sector, while the latter seem to prefer vocational education as these educational pathways are shorter and leads to a more rapid entry on the labour market.

Worth to be mentioned that data evidence a switch of preferences among young male (under 25 years old - the left side of the decision tree and also under 31 years old - the right side) from vocational education that traditionally lead to employment in male-dominated sectors to general education that increase the prospects for academic achievements.

General-oriented education provides skills needed for academic achievements, while vocational-oriented ones aims to train for labour market needs. Ideally, these tracks should be equally valorised and the stratification of pupils should be based on ability, but the findings point to a significant different reality. In Romania, vocational education seems to be less a choice and rather a destination for those coming from households struggling with different socioeconomics problems, irrespective of their gender and personal aspirations, increasing the risks of school dropout or mismatched employment in jobs requiring different qualification or even low level of education.

As income, education and gender continue to explain a high share of preferences for vocational vs. general education, the individualisation of educational paths remains limited in Romania. Coherent reforms aiming to improve the both quality and equity of education and a stronger implication of social partners would support a better tracking by ability of students and improved outcomes in long term.

\section{References}

[1] Arum, R., and Shavit, Y. (1995). Vocational education and the transition of men and women from school to work, Sociology of Education, 68, 187-204. 
[2] Atkinson, E. J., \& Therneau, T. M. (2000). An introduction to recursive partitioning using the RPART routines. Rochester: Mayo Foundation.

[3] Bishop, J., \& Mane, F. (2004). The impacts of career-technical education on high school labor market success, Economics of Education Review, 23, 381-402

[4] Breiman L., Friedman J. H., Olshen R. A., and Stone, C. J. (1984) Classification and Regression Trees. Wadsworth.

[5] CEDEFOP (2017). Changing conceptions of Vocational Education and Training - Results of a survey among European VET experts. Cedefop project 'Changing nature and role of vocational education and training in Europe' - Working paper 2. http://www.cedefop.europa.eu/files/wp2_changing_conceptions_of_vet_survey.pdf.

[6] Estévez-Abe, M. (2001). Labor Markets, Public Policies and Gender Equality: The Varieties of Capitalism Perspective and Beyond, http://citeseerx.ist.psu.edu/viewdoc/download?doi=10.1.1.581.8616\&rep=rep1\&type=pdf.

[7] Giret, J. (2011). Does vocational training help transition to work? The 'New French Vocational Bachelor Degree', European Journal of Education, 46, 244-256.

[8] European Commission (2014) Special Eurobarometer 417. European area of skills and qualifications, conducted by TNS Opinion \& Social for European Commission. http://ec.europa.eu/commfrontoffice/publicopinion/archives/ebs/ebs_417_en.pdf

[9] European Commission (2011) Special Eurobarometer 369. Attitudes towards vocational education and training, conducted by TNS Opinion \& Social for European Commission. http://ec.europa.eu/commfrontoffice/publicopinion/archives/ebs/ebs_369_en.pdf.

[10] Heijke, H., Meng, C., and Ris, C. (2003). Fitting to the job: the role of generic and vocational competencies in adjustment and performance, Labour Economics, 10, 215-229. http://dx.doi.org/10.1787/eag-2012-en.

[11] Mane, F. (1999). Trends in the payoff to academic and occupation-specific skills: the short and medium run returns to academic and vocational high school courses for non-college-bound students, Economics of Education Review, 18, 417-437.

[12] Milborrow, S. (2016). Plotting rpart trees with the rpart. plot package.

[13] Müller, W. and Gangl, M. (2003). Transitions from Education to Work in Europe: The Integration of Youth into EU Labour Markets, Published to Oxford Scholarship Online, DOI:10.1093/0199252475.001.0001.

[14] Nilsson, A. (2010). 272Vocational education and training - an engine for economic growth and a vehicle for social inclusion? International Journal of Training and Development 14:4ISSN 1360-3736.

[15] OECD, 2012, Education at a Glance 2012: OECD Indicators, OECD Publishing.

[16] Therneau, Atkinson, Ripley (2018), Package rpart. https://cran.rproject.org/web/packages/rpart/rpart.pdf

[17] Verhaest, D., Baert, S. (2015). The Early Labour Market Effects of Vocational Higher Education: Is There a Trade-off? Discussion Paper no. 9137, IZA. 